\title{
Understanding Education on China's Belt and Road Initiative: A Cultural Political Economy Approach
}

\author{
Bowen $X U \mid$ ORCID ID: 0000-0002-1793-282X \\ Faculty of Education, University of Cambridge, 184 Hills Road, Cambridge \\ $\mathrm{CB} 28 \mathrm{PQ}$, UK \\ bx223@cam.ac.uk
}

\begin{abstract}
The Chinese Belt and Road Initiative (BRI) is a state-driven development campaign that promote economic integration and infrastructure building across Eurasia and beyond, aiming to reconnect countries and revive the prosperity of the historical Silk Road region. Since its inception in 2013, there has been a growing literature surrounding the initiative, yet the studies of education within the BRI context remain relatively under-researched. This paper aims to explore such connection by undertaking the task through a combination of policy review, semi-structured interviews, and empirical fieldwork data. It adopts a Cultural Political Economy theoretical framework to analyzes how education policy and practice has been positioned, constructed, and coordinated in relation to the wider cultural political economy in assisting the BRI planning and development. Against the background of China's resurgence as a global power and its ambition in reinvigorating the Silk Road, I argue that the strategic positioning of education into the BRI represents a constructive force in imagining, empowering, and materializing the New Silk Road Project. This reveals education and its multifaced properties in promoting cultural outreach, fulfilling political obligation, and accelerating economic growth in line with the overall BRI building.
\end{abstract}

\section{Keywords}

Belt and Road Initiative - education - China - cultural political economy 
In the fall of 2013, Chinese President Xi Jinping proposed a global effort which has now become widely known as the "One Belt One Road" (овов), later renamed the "Belt and Road Initiative" (BRI). It refers to a combination of activities that aimed at building the land-based Silk Road Economic Belt and the ocean-going 21st century Maritime Silk Road. Since its birth in late 2013, the Belt and Road has begun to attract the attention of political scientists and economic analysts at a global scale. Yet, what this initiative means for education has largely been neglected in the extant literature, with a few exceptions (Kirby \& van de Wende, 2019; Peters et al, 2019). Given the increasing power of China and its international presence, the extent to which has education been implicated into China's resurgence deserves urgent scrutiny. To fulfill this gap, this paper draws from a larger, empirically driven project which aims to develop understanding about the role that education plays within the BRI context, highlighting the complexity, multiplicity and multi-dimensional understandings of the BRI. The broader aim of the research is to examine the interconnections between education and the BRI, and the specific questions that guided the research are:

1. What policies has the Chinese government adopted to incorporate education into the BRI design?

2. How can we understand education arrangement within the BRI context in relation to the wider social change?

3. In what ways might education policy and practice influence, or be influenced by, processes of cultural, political, and economic dynamics within and beyond China?

Drawing on a combination of documentary analysis, semi-structured interviews, and existing theoretical framings, I argue that education is an integral part of the BRI by showing how education has been designated as a crucial component in the BRI imaginary to facilitate the BRI materialization. Education should be understood as a complex and evolving entity that is rationalized and shaped by the wider interactive process involving a combination of cultural, political, and economic factors and dynamics in its formation. This paper also suggests that there is a need to advance education research theorization through interdisciplinarity.

The remaining of the paper is to be organized in three parts. It begins with a review of theoretical positioning and methodological choices that frame and

* The author would like to acknowledge Professor Susan Robertson for her kind support and guidance. 
drive the study. The proceeding section attempts to sketch out the emerging terrain of education on the New Silk Road, at both policy terms and in practice. The subsequent section applies theoretical tools to an analysis, revealing how the broader dynamics of cultural political economy have given rise to various kinds of education initiatives that emerged out of the BRI. In doing so, it points out that these changing dynamics in wider social spheres at regional and global scales are fundamental to understanding education, affecting the emerging shape and form of it, and co-constituting the BRI development.

The work of cultural political economy (CPE) has been developed by a group of Lancaster scholars who takes "the cultural turn" in political and economic studies with the intention of bridging the studies of critical political economy and critical semiotic analysis (Sayer, 2001; Jessop. 2004, 2009; Jessop \& Sum, 2013). Further endeavors have been taken to adopt this approach for analyzing education, yet the challenge is that both the tendency of reducing the collective to a single element and the narrowly defined meaning of CPE makes it an incomplete theoretical reading. Robertson and Dale (2015) incorporate a critical orientation into the cultural political economy and updates its meaning and extend its application to studying globalization of education. In Robertson and Dale's account, culture indicates a widen interpretation that goes beyond semiotics and discourse; it relates to meaning-making, identity, affects, experiences, ideology, and civilizational projects. Politics means the dynamics of power movement within and beyond government/governance to all relations of authority or influence between social actors at multiple levels, consisting of governing institutions, foreign policy to region-building. Economy is concerned with value, forms of exchange of value in recognized and non-recognized markets. This novel analytical framework has positioned education at the core of analysis through a three-dimensional interactive lens, offering a fuller account of reading of education through the concept of collegiality. These assumptions are built into critical realist's perspectives in examining how distinct kinds of determinations (cultural, political and economic) work on, in and through an "education ensemble" (Robertson and Dale, 2015). By this it refers to the constellation of different elements - culture, politics and economy - which give rise to particular kinds of education moments or events. CCPEE draws upon a critical realist' social ontology, which intend to make sense of the ways in which structuring mechanisms and conditions in contexts lead to particular outcomes (Sayer, 2001; Robertson \& Dale, 2015). My application of CCPEE in 
studying education in the context of the BRI should be viewed as an outcome of the multiple determinations of generative mechanisms, manifesting itself in the form of education policy and development at the observable, empirical level, against the backdrop of shifting world politics. I resonate with what Robertson (2012) concludes as CCPEE helps to see "education as part of societies, it does not sit outside of it" - by not simply 'adding' education to CPE, but by critically viewing education as being both constituted by and connected to cultural, economic and political dynamics and processes" (p.4).

Methodologically, this study employs a qualitative research design underpinned by both documentary analysis and in-depth simi-structured interviews. An extensive range of documents were collected from a number of sources that include key official policy documents such as government reports, official website coverage from the Ministry of Education (MOE), leaders' speeches, and legislation; media reports, and secondary documents consist of scholarly publications and internet resources; as well as institutional and local/provincial administrations' s policy statements.

In addition, this study also incorporates sixteen semi-structured interviews conducted between late 2018 and early 2019 at nine Chinese tertiary institutions. Criterion sampling was used, key informants and interviewees were approached and purposively sampled. All sampling institutions have well-established academic reputations, and have within their institutions academic experts undertaking policy studies or engaged in Belt and Road research. Four of the visited institutions have already taken concrete steps to consolidate education and BRI connections within their respective institutions. Amongst those interviewed are scholars, administrative staff, managers from and state officials from China's MOE. Interviews were conducted in Mandarin Chinese, lasting approximately 1 hour each. All transcripts and documents were thematically analyzed to uncover emerging themes in relation to research questions. Interview questions included the Chinese government policies on BRI education, China's education policymaking and wider social change, the role of education in reviving the Silk Road, higher education internationalization in the BRI context, and individual institutions' response to MOE'S BRI policy documents. Interview analysis focused on the questions asked, themes emerged out of the analysis were then used for interpretation using the adopted theoretical framework as described earlier.

Qualitative documentary analysis provides official policy guidance to depict the overall picture, whilst rich interview data offers detailed insights regarding BRI education policy and development from institutional and individual perspectives. Interviews contextualize the findings from the documents and policy review, corroborating and complementing research findings and analysis. 
Since President Xi became China's new leader in 2012, ambitious plans and policy initiatives for national, regional, and international development were gradually released as to catering the changing internal and external social, political and economic conditions. Accompanying the initiation of the BRI, numerous policy documents have been put into place in guiding and governing new developments in the new era. China's education policymaking has also witnessed important changes during this period alongside the rise and re-emergence of the country as a global superpower. Education is to be conceptualized as part of the bigger social policy package aimed at transforming the wider outlook of Chinese society, reflecting the transformative nature of the Chinese state in recent years. Three policies documents promogulated over this period highlight the importance of education in enabling the BRI architecture. These are shown below.

- $\quad 2015$ Vision and Actions on Jointly Building Silk Road Economic Belt and 21st-Century Maritime Silk Road

- 2016 Opinions on the Work of the Opening-Up of Education in the New Era

- $\quad 2016$ Education Action Plan for the Belt and Road Initiative

Vision and Action is regarded as the most comprehensive policy document for the BRI, jointly released by three Chinese government departments National Development and Reform Commission, the Ministry of Foreign Affairs and the Ministry of Commerce. The other two are education-specific tailored policies that aims to provide overviews and guidance for institutions in planning and reforming their own practice with regards to education opening-up and international collaboration in the BRI context. The three policies share an overarching theme, best summarized as being open, cooperative, and outward-oriented. China's policy preference towards international education has been consistent with its attitudes towards globalization. The openness is evidenced in policy statements where the Chinese government has made explicit commitment regarding further opening international education sector, boosting scholarship provision for overseas students, and encouraging transnational academic collaboration.

By initiating the BRI, China has been placing an unprecedented demand on itself during the process of reaching out. Whether the interactions with the outside world are economic, political or technological, the success of BRI will always require cross-cultural engagement with people from different culture and civilisations. The Chinese government reiterates the importance of education in upholding "people-to-people" bond - one of the five key connectivity that underpinning the BRI spirits (Vision and Actions, 2015). Education is 
viewed as one of the most effective and efficient means to facilitate various kinds of exchange on and improve the connectivity of the New Silk Road. In that regard, what education could bring to the region is not limited to its capacity in bringing minds and hearts closer or together, but lies on its transformative effect on upholding regional peace and reshaping returns of investment and gain in a long-term and strategic manner. As an integral part of BRI, education is a conduct through which to nurture human talent, expand people-to-people exchange, and facilitate cultural dissemination. China has expressed its willingness to find "corresponding point" so that more Sino-foreign educational collaboration can be established between partners who express, and seek common interests (Action Plan, 2016).

Since 2016, the Ministry of Education has signed memorandum of international cooperation with 14 provinces including Gansu, Ningxia, Fujian, Guizhou and other autonomous regions and municipalities as to establish a ministerial-provincial joint platform for promoting education collaboration on the Belt and Road (MOE, 2018). This joint flatform system enables policy decisions to be emerged through an interactive process involving local, regional and state actors via a multi-level governance structure. This has challenged the traditional assumption that China's policymaking occurs in an uncontested top-down fashion, with decision power rest with a small group of elites from the ruling party whilst the interests of local and public are assumingly systemically excluded. In fact, place-based policy making along geographical context were prioritised as the key consideration, which help to avoid the mentality of "state knows best". Having benefited from the changing governing modes and models, institutions are better placed to integrate their own needs and concerns into reform and maximise their distinctive characteristics in policy coordination and implementation. This has resulted in various kinds of initiatives among Beijing's higher educational institutions, in part as a policy response / enactment. For example, Peking University has launched a new research institute as the scholarly contribution to advancing research related to the BRI. The newly founded institute mobilizes, integrates and revitalizes the university's rich and diversified resources in foresting new type of academic talents, accumulating knowledge and providing support to key countries and regions on the Belt and Road route. Similarly, Renmin University has established its Silk Road School in Suzhou in 2018. It aims to enroll students from the Belt and Road countries and regions in a Masters-level degree course The Contemporary Chinese Studies. This is a key measure by Renmin University to support the BRI in education and provide a response to policy quest (Silk Road School Renmin 
University, 2019). Similarly, the top-ranked Tsinghua University built its One Belt-One Road Strategy Institute in 2017.

Transnational and cross-border institutions emerge and grow in the BRI context, including the Chinese language teaching and training centre - Confucius Institutes and Chinese universities' offshore campus. The establishment of Confucius Institutes is commonly viewed as a sophisticated tool for China to expand its global influence and promote its model of governance through the exportation of its language and culture (Yang, 2010). As a form of cultural diplomacy, Confucius institutes constitutes an importance aspect of China's foreign policy, with the intention to "winning hearts and minds" through the form and practice of language and education. Recent year have witnessed a significant increase in the number of Confucius Institutes, especially in the Belt \& Road region. Mandarin Chinese has become one of the most important languages communicated along the Silk Road route. There have been more than 137 Confucius Institutes and 131 Confucius Chinese-language study classrooms in 53 countries in the region, enrolling more than 46o,ooo learners (the Diplomat, 2017). Moreover, a small number of Chinese higher education institutions are engaged in overseas campus building in the Belt \& Road countries. Examples are Xiamen University's Malaysia Campus, Soochow University in Laos, Bangkok Business School of Yunnan University of Finance \& Management in Southeast Asia (He \& Wilkins, 2018; 2019) and Tongji University's branch campus in Italy (Bellini et al, 2016).

Other education-related projects include the formation of several university alliance such as the University Alliance of the Silk Road, the New Silk Road Law Schools Alliance and the Asian Universities Alliance (Cabanda et al, 2019). These might be interpreted as extensions of China's BRI in the higher education sector, and it is worth noting that China initiated and driving the directions of these different kinds of higher education regional associations whilst manage to transforming its identity from what is often perceived as a "rule-taker" to a "rule-maker". The Silk Road scholarship scheme drafted by the Chinese authority has also contributed to a remarkable rise in the number of international student recruitment. This will help China to achieve its plan for higher education internationalization and meet the target of hosting 500,000 foreign students by 2020 .

\section{Education, Cultural Political Economy and the BRI}

Applying the theoretical framework to examine the ways in which education has been mediated and shaped by a range of external conditions and structural 
mechanisms that are simultaneously cultural (meaning), political (power) and economic (exchange) is the next move of this paper. Making sense of education policy agenda and its forms of development requires the recognition that education is a highly complex and evolving enterprise, which ought to be placed in the wider social world to inspect the multiple, contingent, and constituting properties that giving rise to its emergence and the collegiality in their effects. The proceeding discussion sets a context in which education can be conceived in relation to the convergence of culture, politics, and economy in the process of the BRI production and evolution.

\subsection{Cultural Outreach}

In revitalizing the ancient Silk Road, China intended not simply to re-establish the ancient trade route, but to use the cultural meaning of the Silk Road as a "soft" basis for governing regional and international cooperation. The Silk Road spirit, described as "peace and cooperation, openness and inclusiveness, mutual learning and mutual benefit" is the underpinning philosophy driving the BRI project, with the intention to "promotes practical cooperation in all fields, and works to build a community of shared interests, destiny and responsibility featuring mutual political trust, economic integration and cultural inclusiveness" (Vision and Action, 2015). Chinese politicians including President Xi has spoken about the cultural significance of Silk Road in that the connectivity will not only depends on infrastructure construction the BRI delivers, but also on culture, software such as norms, ideas, rules, institutions and education (Callahan, 2016). In other words, the ultimate success of BRI will require a sense of cultural revitalization as well. Historically, the Chinese had a vast influence over its neighboring countries, which has been well documented throughout history. The ancient Silk Road was the carrier of cultural, religious, and civilizational spread that enabled the Chinese civilization to meet other world civilizations for cultural exchange and cross-cultural hybridization (Griffiths, 2017). However, China's modern-day cultural influence over its territorial boundary has been quite limited, especially in contrast with its export-heavy position in foreign trade and investment (Ying, 2017; Tang, 2017; Wen \& Hu, 2018). So how to reinvigorate a cultural sphere that coexist with the Silk Road for empowering Chinese cultural spread is imperative. Incorporating education as a cultural infrastructure into the BRI design could be an answer.

A number of scholars suggest that the export of education can be viewed as a form of soft power and a way of advancing cultural diplomacy (Yang, 2010; King, 2010; Knight, 2015; Wu, 2018). Indeed, the recent proliferation of Confucius Institute on the Silk Road route is a good example to show the return of China's soft power influence via language and culture teaching and learning. At policy 
level, there has also been efforts to include language-related issues into the systematic education policy planning, revealing how education, culture and soft power have been thoughtfully, systemically planned, integrated and exercised in expanding Chinese cultural outreach globally. Besides the use of language institutes to launch its cultural project, in a new move, Chinese higher education institutions have sought to run collaborative programs and campuses aboard. Several exemplary cases are illustrated earlier, which are seen to be novel phenomena especially when compared to western-centric transnational establishments in Asia and the Middle East. Newly founded institutes offer courses such as Chinese language, Chinese medicine, and Sinology. Knight' (2015, p.8) notion of "knowledge diplomacy" precisely capture the essence of the initiative; that international education can be used for putative mutually beneficial purposes aimed at strengthening relationships between countries through student and staff mobility, and knowledge exchange. More importantly, the most recent transformation in China's identity as a knowledge sender rather than recipient reserve some long standing cultural deficit the country had experienced and boost a sense of cultural pride. One senior scholar said,

higher education in China was mainly inward-oriented in the past. In recent years, Chinese universities become more active in establishing transnational partnerships. This is, of course, individual institutional planning and their own response to the competitive higher education market, but it corresponds to the national policy in encouraging education provision looking outwards. After all, China wants to build world-class university, and it needs to find a sense of presence in the global higher education community to match its rising power statues. (Interviewee)

Central to the argument is that education is ought to be viewed as a cultural asset conducive to strengthening connectivity and for "winning hearts and minds". Developing intercultural understanding through education would therefore help China in boosting cultural influence, gaining cultural confidence, reversing cultural deficit, and wining cultural acceptance, especially so in the BRI context.

\subsection{Foreign Policy}

Education is an intrinsically political subject, particularly so in the broader context of East Asia. The need to position the state and its politics at the center of enquiry for any investigation has become a regional feature. It would be surprising to make the claim that politics has not made impact or penetrate education within the region. The making of education policy on BRI has also 
been colored with Chinese foreign policy mentality. This is most evidenced through an internal, cross-sectoral policy borrowing.

China's principles for international relations are based on The Five Principles of Peaceful Coexistence, which was proposed by the then Chinese premier Zhou Enlai in 1954. This has become one of the most important political ideologies governing China's foreign policy throughout the 2oth century. It proposes China's norms and values based on the five principles of mutual-respect, non-interference, equality, mutual benefits and peaceful coexistence. This has become the major source of China's normative power, and it was effectively diffused by Beijing in enhancing its multilateral cooperation across continents for decades (Zhou \& Esteban, 2018). In 2017, President Xi reiterated the importance of upholding the principles in implementing the BRI during his speech at the opening ceremony of the Belt and Road Forum for International Cooperation in Beijing:

China will enhance friendship and cooperation with all countries involved in the Belt and Road Initiative on the basis of the Five Principles of Peaceful Co-existence. We are ready to share practices of development with other countries, ... What we hope to achieve is a new model of win-win cooperation We have no intention to form a small group detrimental to stability, what we hope to create is a big family of harmonious co-existence (xi, 2017).

Meanwhile, a parallel development in both rhetoric and direction between China's foreign policy and its education policy are observed. Turning back to Action Plan, for instance, discourses such as "mutual understanding", "mutual respect", "mutual learning", "mutual benefits", "mutual trust", "win-win", and "regional peace", are marked with distinct Chinese foreign policy characteristics.

Moreover, in 2013 during his state visit to Indonesia, President Xi proposed to establish the 21st Maritime Silk Road, and spoke about the "China-ASEAN community of shared destiny" at the Indonesian parliament. The project was to create a harmoniously egalitarian regional community and highlight the importance of working with other countries in resolving regional and global affairs. This new concept embraced China's win-win logic, and over time has evolved to be one of the central thoughts under Xi's governing regime, which was enshrined in the Chinese Constitution in 2018. The concept of "community of shared destiny for mankind" refers to a worldview that the globe has increasingly grown into a community where one's destiny is interwoven with that of others (Zhang, 2018). It is therefore anticipated we can only aspire and embrace the future by working with others in the international community to 
promote common development and prosperity; in other words, nation states are bound together for their shared interest, destiny and responsibility. In a similar way, "community of shared destiny for mankind" as a political ideology is now being injected into the making of education.

The countries along the routes will work together to deepen mutual understanding, expand openness, strengthen cooperation, learn from each other, to pursue common interests, face our shared future, shoulder common responsibilities, and work concertedly to build a Belt and Road educational community. (Action Plan, 2016)

It is therefore important to note that education does not exist independently from the wider social environment, and certainly subject to political influence. In the case of the BRI, political leaders' thoughts were borrowed and travelled across sectors within the country, permeating with respective sectoral concerns in ordering the sectoral development priority in line with the national agenda. To understand education and its form, shape, and ways of development, it is necessary to understand the political context in which it is situated.

\subsection{Economic Reconfiguration}

China has enjoyed an unprecedented economic growth over the past four decades, yet this economic success was largely attributed to massive export-oriented manufacturing industries, cheap labor and large-scale urbanization, and therefore cannot be taken as a sustainable way forward. This is especially true since the 2008 global financial crisis. The global financial crisis has had a significant impact on China's economic performance. China's western trading partners experienced staggering growth, resulted in declining purchasing capacity which has in turn hampered Chinese exports. Against that background, China's economic development has reached a bottleneck. As a way forward, economists argue that the BRI could be devised to reconfigure China's economic structure to sustain its continued economic growth in the post-crisis era (Huang, 2016). The rationale underpinning this argument is that most countries along the Silk Road route are emerging economies whose total population amounts to some 4.4 billion (two third of the global population) yet whose markets are only currently accounting for approximately one third of global Gross Domestic Product (GDP) at 21 trillion US dollars (Lim, 2016; Ferdinand, 2016). Undoubtedly, the region projects high demand for cross-border trade and investment, given that its current population is not commensurate with its global economic share, thus offering vast opportunities for predictable economic growth. In this context, Chinese individuals, 
along with private and state companies, are encouraged to "go out" to search for offshore economic opportunities in the Belt \& Road countries.

Although the Belt \& Road region is seen as economically promising, practical challenges remain. The highly complex region means countries within this vast territory display huge differences in terms of religion, language, politics, and legal system. whilst BRI-related projects being initiated and advanced, companies and enterprises will inevitably encounter various issues along the way. Difficulty is also likely to be exacerbated by the rapid development in foreign trade and investment. Accompanying the macroeconomic adjustment there is a genuine demand for nurturing human talents. This is simply because economic transition, manufacturing upgrading and cross-border collaboration cannot be realized without a well-educated workforce. In this context, education is seen as being central to achieving further growth, building alternative and more sustainable economy. This new economic imaginary will also require new types of skills, knowledge, and expertise. It is likely to include, but not limited to high proficiency in foreign language, knowledge in mastering cutting-edge technology, and intercultural communication capacity. Those who are educated - as having talent - should have expertise in business, culture, and language along both sides of the trading route are highly desirable. As a response, talent cultivation has been prioritized. In Action Plan, the word "human talent" appeared 20 times. The definition of talents comprises academics, technicians, language experts and various kinds of much needed workers. The mechanisms for cultivating talents are innovative and open to collaboration in partnership with industrial and commercial enterprise. In addition, the establishment of "Silk Road Scholarship" is an exemplified measure that aimed at training leading intellectuals and specialists for the B RI development. More specifically, Chinese universities are provided with scholarships for recruiting outstanding talents from the Belt and Road countries to sponsor their degree studies in China. Silk Road Two-Way Student Exchange Enhancement Programme (Action Plan, 2016) places equal importance on sending domestic students aboard to the Belt and Road region.

It is therefore important to see education as an important "economy" in its own right, transforming modes of production, creating new values, and upgrading knowledge-based communities. The demand for nurturing talents has become a global trend in ever competitive and globalized world. China's quest for building BRI requires an economic imaginary, and education has been strategically positioned within it. Education is seen as a means through which to improve the life quality of regional population, establish a knowledge-based regional hub, and further facilitate regional modernization with the backup of rich human resources. The underling logics is human capital theory (Becker, 
1993). China's adoption of human capital has been aligned with the country's objective of modernization and its own experience of development. For China, development is the hard truth (Deng, 1992), and education has an instrumental role to play in modernization. Arguably, to understand the role of education in the BRI, it is crucial to recognize and unveil its transformative effects on reconfiguring the wider regional economy.

\section{5}

\section{Concluding Remarks}

This paper set out to investigate, within the context of BRI, how education has been incorporated in policy planning and touch upon the extent to which policy initiatives have been materialized in practice. Positioning the analysis in an interdisciplinary paradigm, the paper reflects upon the prospects, processes and outcomes of education policymaking and development on the New Silk Road. It points out that education arena is an open, dynamic, complex, changing and contested one where different actors from different sectors congregate, interact, negotiate, comply and compromise in their searching for the best "converging interest" in line with the national development agenda. Thus, education as a complex social activity cannot be fully explained and justified via any single theory or single lens. The strategic positioning of education into the Belt and Road is best to be seen as a collective unity or ensemble that subject to multiple and contingent determinations of social processes involving meaning making, power relations, and forms of exchange. In problematizing education as a constituent in the making of the BRI, there is a need to go beyond the scope of education disciplinary boundary, and to acknowledge the broader social context that shaping China's resurgence and the variegated cultural political economy substantiating it. Given the strong momentum of the BRI, it is likely to expect more education-related initiatives to be revealed and developed in the foreseeable future. This paper, however, is to take the very first few steps onto the uncharted territory, depicts the emerging landscape of rapidly changing Chinese and global education sphere and to illuminate future researchers in their search for what promise to be intellectually stimulating research in the years and decades to come.

\section{References}

Becker, G, S. (1993). Human capital: A theoretical and empirical analysis, with special reference to education (3rd ed.). Chicago, IL: University of Chicago Press. 
Bellini, N., Pasquinelli, C., Rovai, S., \& Tani, S. (2016). The Local Embeddedness of Foreign Campuses: The Case of Tongji University in Florence. Journal of Studies in International Education, 20 (4), 371-385.

Cabanda, E., Tan, E, S., \& Chou, M-H. (2019). Higher education regionalism in Asia: what implications for Europe. European Journal of Higher Education, 9 (1), 87-101.

Callahan, W, A. (2016). China's "Asian Dream": The Belt Road Initiative and the new regional order. Asian Journal of Comparative Politics, 1 (3), 226-243.

Deng, X. P. (1992). Key points of talks at Wuchang, Shenzhen, Zhuhai, Shanghai etc. In X Deng, (Ed), The Editorial Committee of the cPccc's Party Literature, vol 3, 370-383. Beijing: People's Publishing House.

Education Action Plan for the Belt and Road Initiative. (2016). The Ministry of Education of the People's Republic of China. Retrieved from https:/eng.yidaiyilu. gov.cn/zchj/qwfb/30277.htm.

Ferdinand, P. (2016). Westward ho - the China dream and 'one belt, one road': Chinese foreign policy under Xi Jinping. International Affairs, 92 (4), 941-957.

Griffiths, R, T. (2017). Revitalising the Silk Road: China's Belt and Road Initiative. Leiden: HIPE Publications.

He, L., \& Wilkins, S. (2018). Achieving Legitimacy in Cross-Border Higher Education: Institutional Influences on Chinese International Branch Campuses in South East Asia. Journal of Studies in International Education, 22(3), 179-197.

He, L., \& Wilkins, S. (2019). The Return of China's Soft Power in South East Asia: An Analysis of the International Branch Campuses Established by Three Chinese Universities. Higher Education Policy, 32, 321-337.

Huang, Y. (2016). Understanding China's Belt \& Road Initiative: Motivation, framework and assessment. China Economic Review, 40, 314-321.

Jessop, B. (2004). Critical Semiotic Analysis and Cultural Political Economy. Critical Discourse Studies, 1 (2), 159-174.

Jessop, B. (2009). Cultural Political Economy and Critical Political Studies. Critical Policy Studies, 3 (3), 336-356.

Jessop, B., \& Sum, N.-L. (2013). Towards a cultural political economy: putting culture in its place in political economy. Cheltenham: Edward Elgar.

King, K. (2010). China's cooperation with Africa, and especially South Africa, in education and training. A special relationship and a different approach to aid? Journal of International Cooperation in Education, 13 (2), 73-87.

Kirby, W., \& van der Wende, M. (2019). The New Silk Road: implications for higher education in China and the West? Cambridge Journal of Regions, Economy and Society, 12, 127-144.

Knight, J. (2015). Moving from soft power to knowledge diplomacy. International Higher Education, 8o, 8-9. 
Lim, W, X. (2016). China's One Belt One Road Initiative: A Literature Review. In T, W, Lim ., H, L, Chan ., H-Y Tseng, . \& W, X Lim, (Eds.), China's One Belt One Road Initiative. London: Imperial College Press.

Ministry of Education (2018, June 26). Educational opening up to provide services for the Belt and Road. Retrieved from http://en.moe.gov.cn/Specials/Review/ Facts_2147443481/201806/t2018o626_341024.html.

Peters, M, A. (2019). The Chinese Dream, Belt and Road Initiative and the future of education: A philosophical postscript. Educational Philosophy and Theory, https:// doi.org/10.1080/oo131857.2019.1696272.

Robertson, S. L. (2012, April). Global governance of teacher's work: reflections on a cultural political economy of education. Paper presented at the Annual Conference of the Comparative and International Education Society, San Juan, Puerto Rico.

Robertson, S, L., \& Dale, R. (2015). Towards a 'critical cultural political economy' account of the globalising of education. Globalisation, Societies and Education, 13(1), 149-170.

Sayer, A. (2001). For a Critical Cultural Political Economy. Antipode, 33 (4), 687-708.

Silk Road School Renmin University (2019, March 12). Retrieved from http://srs.ruc. edu.cn/English/About/AboutUs/index.htm.

Tang, Z. (2017). Implications in the era of building Confucius Institutes from a global perspective. Chinese Education \& Society, 49(6), 385-39o.

The Diplomat. (2017, November 25). One Belt, One Road, One Language? Retrieved from https://thediplomat.com/2017/o5/one-belt-one-road-one-language/.

Vision and Actions on Jointly Building the Silk Road Economic Belt and the 21st Century Maritime Silk Road. (2015, June 25). National Development and Reform Commission, Ministry of Foreign Affairs and Ministry of Commerce of the People's Republic of China. Retrieved from http://en.ndrc.gov.cn/newsrelease/201503/ t20150330_669367.html.

Wen, W., \& Hu, D. (2018). The Emergence of a Regional Education Hub: Rationales of International Students' Choice of China as the Study Destination. Journal of Studies in International Education, 23 (3), 303-325.

$\mathrm{Wu}$, H. (2018). Three dimensions of China's "outward-oriented" higher education internationalization. Higher Education, 77, 81-96.

Xi, J. P. (2017, May 14). Work Together to Build the Silk Road Economic Belt and The 21st Century Maritime Silk Road. A keynote speech at the opening ceremony of the Belt and Road Forum (BRF) for International Cooperation in Beijing, China. Retrieved from http://www.xinhuanet.com//english/2017-05/14/c_136282982.htm.

Yang, R. (2010). Soft power and higher education: An examination of China's Confucius Institutes. Globalisation, Societies and Education, 8, 235-245. 
Ying, W. (2017). Review of the Confucius Institutes' strategy for the dissemination of Chinese culture. Chinese Education \& Society, 49(6), 391-401.

Zhang, D. (2018). The Concept of 'Community of Common Destiny' in China's Diplomacy: Meaning, Motives and Implications. Asia and the Pacific Policy Studies, $5(2), 196-207$.

Zhou, W., \& Esteban, M. (2018). Beyond Balancing: China's approach towards the Belt and Road Initiative. Journal of Contemporary China, 27 (112), 487-501. 